\title{
¿REGLAS DEL ENTENDIMIENTO? ACERCA DE LA “JURIDIFICACIÓN” DE LA COMUNICACIÓN EN LA PRAGMÁTICA UNIVERSAL DE JÜRGEN HABERMAS*
}

\author{
Juan Pablo Mañalich R.
}

El artículo se ocupa de la peculiar manera en que la concepción habermasiana del lenguaje reconstruye la normatividad de las condiciones del entendimiento, proyecto que encierra una hipóstasis de la comunicación. La exploración crítica de esta hipóstasis, inspirada en una cierta lectura de Wittgenstein y Davidson, se centra en la premisa de que la posibilidad de entendimiento dependería del ejercicio de una competencia para la aplicación de reglas pragmáticas universales, compartida por los participantes en la comunicación. El cuestionamien-

Juan Pablo Mañalich. Doctor en derecho, Universidad de Bonn (2008); licenciado en ciencias jurídicas y sociales, Universidad de Chile (2004). Profesor de derecho penal, Universidad de Chile. Entre sus publicaciones se cuentan las monografías Nötigung und Verantwortung (Baden-Baden: Nomos, 2009), Autotutela del Acreedor y Protección Penal del Deudor (Ediciones Jurídicas de Santiago, 2009) y en conjunto con Urs Kindhäuser, Pena y Culpabilidad en el Estado Democrático de Derecho (Lima: Ara, 2009).

* El artículo constituye una versión ampliada de la ponencia presentada el 9 de septiembre de 2009, en el marco del congreso celebrado con ocasión de los ochenta años de Jürgen Habermas, organizado conjuntamente por la Universidad Diego Portales y la Universidad Adolfo Ibáñez. El autor agradece las muy prolijas y valiosas sugerencias, tanto de forma como de sustancia, recibidas de los dos árbitros anónimos que intervinieron en el proceso. A uno de ellos debe agradecer especialmente por haber contribuido, con toda probabilidad, a hacer mucho más comprensible el argumento global. El autor agradece también a Guillermo Silva Olivares, egresado de la Facultad de Derecho de la Universidad de Chile y ayudante del Departamento de Ciencias Penales, por su muy valiosa ayuda en el trabajo de edición del manuscrito.

Estudios Públicos, 119 (invierno 2010). 
to de esa premisa, tal como se intenta mostrar hacia el final, no amenaza el carácter público del lenguaje, pero sí puede redefinir su normatividad específica.

Palabras clave: pragmática universal; filosofía del lenguaje; entendimiento; acción comunicativa; actos ilocucionarios; reglas constitutivas; autonomía del significado; principio de caridad.

\section{El modelo de los dos mundos versus el modelo de la performance}

口 determinada articulación de los ejes de la filosofía del lenguaje o, más propiamente, de la reflexión filosófica ocupada del lenguaje, en su decurso a través del siglo XX. La tesis planteada por Krämer resulta sorprendente, pues la misma, de ser plausible, habría de traer consigo una redefinición significativa de los intentos más habituales de mapeo.

Krämer sostiene que bajo la superficie de las clasificaciones tradicionales, las contribuciones más emblemáticas que se registran durante el siglo XX pueden ser divididas en dos bloques fundamentales: aquellos que validan el denominado "modelo de dos mundos" para dar cuenta de la ontología del lenguaje, y aquellos que lo impugnan ${ }^{1}$. El primero de estos bloques valida ese modelo ontológico dualista por medio de una distinción categorial entre lenguaje (Sprache) y habla (Sprechen), en el sentido de la distinción entre un esquema (idealizado) y su actualización, es decir, entre esquema y uso. La comunicación, entendida como cualquier instancia de habla exitosa, sólo podría ser reconocida como tal en atención al modo en que en ella se realizan sus propias condiciones de posibilidad, las cuales determinarían, entonces, lo que cuenta como lenguaje ("puro"). Entre los representantes más prominentes de tal compromiso ontológico con un modelo de dos mundos, que expresaría una imagen intelectualizada del lenguaje, figurarían Ferdinand de Saussure, Noam Chomsky, John Searle y Jürgen Habermas.

El bando opuesto incluiría, según Krämer, un conjunto bastante heterogéneo de concepciones cuyo parecido de familia — para emplear

\footnotetext{
${ }^{1}$ Krämer (2001), pp. 9-15.
} 
la terminología de uno de sus más conspicuos exponentes- se encontraría en un rechazo a esa imagen intelectualizada que asume la distinción ontológica entre esquema y uso. Lo característico de este segundo conjunto de concepciones sería, por ende, un compromiso con lo que Krämer denomina un "modelo de la performance", en el cual el uso cobra primacía sobre el esquema: "es en la dimensión del uso donde aparece una dinámica que tiene la fuerza de modificar el esquema en su realización" ${ }^{2}$. Es decir: el habla, entendida como cualquier episodio de comunicación exitosa, no puede ser conceptuada como una instancia de realización de un lenguaje "puro". De esto se sigue que carecería de sentido asumir la existencia de un lenguaje con anterioridad e independencia del habla. Entre los representantes más connotados de esta orientación anti-intelectualista se contarían Ludwig Wittgenstein - “los dos"-, J. L. Austin, Donald Davidson, Jacques Lacan, Niklas Luhmann, Jacques Derrida y Judith Butler.

Lo anterior sugiere cuán revisionista puede llegar a ser la línea demarcatoria trazada por Krämer. Basta para ello con atender al hecho de que los dos filósofos más inequívocamente asociados al desarrollo de la moderna teoría de los actos de habla - Austin y Searle- queden situados en bandos encontrados. Con su hallazgo del carácter "realizativo" o "performativo" de determinadas emisiones lingüísticas ${ }^{3}$, Austin se encontraba ciertamente muy lejos de abrazar la pretensión taxonómica que llevaría a Searle a proponer una clasificación exhaustiva de las distintas fuerzas ilocucionarias. En otras palabras: el compromiso de ambos con el "giro pragmático" operado en la filosofía del lenguaje no alcanza a modificar el hecho de que sólo Searle, y no Austin, exhibe un compromiso con un modelo ontológico de dos mundos cuando distingue entre las condiciones universales para la realización exitosa de un determinado tipo de acto — condiciones fijadas, por lo demás, en reglas constitutivas-, y la instanciación (uso) de esas condiciones a través de la emisión de uno o más actos de habla particulares. Como habrá de verse todavía, éste es un antecedente de máxima relevancia para la comprensión de las implicaciones ontológicas del programa habermasiano de una pragmática universal.

\footnotetext{
${ }^{2}$ Ibídem, p. 13.

${ }^{3}$ Ello apunta a la circunstancia (obvia) de que al decir algo un hablante puede estar haciendo o realizando algo distintivo, según se examinará más abajo.
} 
Desde el punto de vista de un modelo de la performance, la afirmación de la existencia de un esquema de lenguaje "puro" constituye una hipóstasis ${ }^{4}$. Pues el compromiso con un modelo de la performance se traduce en la proposición de que el esquema instanciado (o "realizado") a través de su respectiva aplicación concreta siempre resulta potencialmente superado o desbordado por ésta ${ }^{5}$.

Una revisión crítica de la concepción habermasiana del lenguaje, que asuma el punto de vista de un modelo de la performance, puede estar en condiciones de mostrar cómo esa concepción exhibe, en definitiva, una tendencia a la "juridificación" de la comunicación, esto es, a producir una imagen de ésta bajo la cual hablar con otros consistiría en entablar "pretensiones" y contraer "obligaciones". Y si ello es efectivo, entonces el programa habermasiano de una fundamentación de la normatividad sobre la base de las condiciones del entendimiento lingüístico, en términos de la así llamada "ética del discurso", podría verse enfrentado a la objeción de una petición de principio.

\section{La pragmática universal}

Lo que cabe examinar ahora es la manera en que la concepción del lenguaje articulada en la obra filosófica de Jürgen Habermas se halla efectivamente comprometida con lo que Krämer denomina una ontología de dos mundos. Y aquí es relevante enfatizar la conexión que Krämer pretende hallar entre semejante modelo ontológico, por un lado, y un determinado logo-centrismo atribuido al lenguaje, por otro. Pues lo genuinamente distintivo del programa habermasiano de reconstrucción de las condiciones del entendimiento se halla en la tesis de que la racionalidad inmanente a la comunicación lingüística estaría inscrita en la reflexibilidad potencial de sus condiciones de posibilidad. Es decir, el carácter racional de ese proceso de reconstrucción se encuentra, en un sentido sumamente preciso, en una relación de interdependencia con el carácter racional del objeto de esa misma reconstrucción.

${ }^{4}$ Por "hipóstasis" cabe entender una maniobra (distintivamente filosófica) consistente en atribuir existencia "sustancial" a aquello de lo cual se pretende dar cuenta explicativamente, lo cual, al menos según Wittgenstein, constituye una importante fuente de confusión filosófica: "un sustantivo nos hace buscar una cosa que se corresponda con él”. Así Wittgenstein (1960), p. 1.

${ }^{5}$ Krämer (2001), p. 12.

${ }^{6}$ Véase Habermas (1998), pp. 57-134. 
En esto consiste la fundamental distinción habermasiana entre comunicación y discurso. Como explica Krämer, en el contexto de la filosofía de Habermas, la referencia del lenguaje a la acción — esto es, su dimensión pragmática - aparece como una doble disposición: el lenguaje no sólo hace posible una modalidad diferenciada de acción orientada al entendimiento - lo que Habermas llama, técnicamente, "acción comunicativa"-, sino también una interrupción de ésta, precisamente a través del discurso 7 . Pues por "discurso" Habermas entiende una forma de uso del lenguaje orientada a la tematización y problematización de aquellas pretensiones de validez que, en el contexto de la acción comunicativa cotidiana, los hablantes reclaman para lo que dicen, y de cuyo reconocimiento por parte del respectivo oyente dependería la posibilidad de entendimiento.

Semejante programa de reconstrucción de las condiciones de racionalidad inmanentes al habla cotidiana, es lo que Habermas entiende por "pragmática universal". Tales condiciones fijarían el modo en que es posible que los participantes en la comunicación efectúen emisiones que cuenten como instancias particulares de actos de habla cuya fuerza específica es dependiente, a su vez, de la entablación explícita o implícita de determinadas pretensiones universales de validez. En palabras del propio Habermas, la pragmática universal es "el programa de investigación dirigido a reconstruir la base universal de validez del habla"8. Lo que esto promete, entonces, es la identificación de aquellas condiciones de la racionalidad comunicativa que se hallan ya incrustadas en la posibilidad humana, evolutivamente adquirida, de entendimiento lingüístico. $\mathrm{Y}$ a través de la generalización de esas condiciones tendría que resultar perfilado un modo distintivo de racionalidad, a saber: la racionalidad de la acción comunicativa, entendida - por oposición a la racionalidad de la acción estratégica- como la racionalidad propia de la efectiva coordinación consensual de los planes de acción de los participantes en la comunicación. Lo cual descansaría, a su vez, en la capacidad de los participantes de tomar posición crítica frente a determinadas pretensiones (universales) de validez que los interlocutores se atribuyen recíprocamente.

Lo anterior pone de manifiesto, desde ya, la efectividad del compromiso de Habermas con lo que Krämer llama el modelo de los dos

\footnotetext{
${ }^{7}$ Krämer (2001), p. 74.

${ }^{8}$ Habermas (1984), p. 357.
} 
mundos, precisamente porque la identificación de aquellas pretensiones universales de validez susceptibles de crítica depende, en un primer paso reconstructivo, del reconocimiento de tipos puros - es decir, fuertemente idealizados - de actos de habla a través de cuya realización un hablante puede entablar una determinada pretensión de validez, cuyo desempeño sea susceptible de crítica. Ello se vuelve particularmente claro si se examina la manera en que Habermas, hacia el final del "interludio primero" de su Teoría de la Acción Comunicativa, esboza la posibilidad de un tránsito desde una pragmática formal hacia una pragmática empírica, lo cual exigiría, entre otras cosas,

a) dar cabida, además de los modos fundamentales, "a la diversidad de fuerzas ilocucionarias que forman la red de interacciones posibles plasmadas y estandarizadas en las diversas culturas y en las diversas lenguas particulares"; así como

b) dar cabida, además de la forma estándar, "a otras formas de realización lingüística de los actos de habla"; así como

c) dar cabida, además de los actos de habla directos, "a las emisiones indirectas, translaticias y ambiguas, cuyo significado ha de inferirse del contexto"; así como

d) hacer extensivo el análisis "de los actos de habla aislados (y de las tomas de postura de afirmación o negación) a secuencias de actos de habla, a textos o diálogos, de modo que resulten visibles y puedan tenerse en cuenta las 'implicaciones conversacionales"'; así como, finalmente

e) introducir, junto a las actitudes (ilocucionarias) básicas, "una actitud realizativa de tipo global para dar cuenta del hecho de que con cada acto de habla los participantes en la comunicación se refieren simultáneamente a algo en el mundo objetivo, en el mundo social y en el mundo subjetivo".

En la enunciación precedente se hace reconocible cuán comprometida está la concepción habermasiana del lenguaje con una ontología de dos mundos, en términos de la cual los episodios particulares de habla habrían de ser medidos bajo lo que el propio Habermas llama "la forma estándar". De ahí que Habermas postule una demarcación entre lenguaje y habla, cuyas respectivas unidades atómicas serían la oración

${ }^{9}$ Habermas (1999), pp. 421-422. 
y la emisión (de una oración) ${ }^{10}$. Especialmente significativa resulta ser aquí la observación posterior en cuanto a que el tránsito hacia una pragmática empírica requeriría una ampliación del alcance del programa reconstructivo a emisiones indirectas y ambiguas, cuyo significado habría de inferirse del contexto. Pues lo que esto sugiere, a contrario sensu, es que el significado de las emisiones que sí satisfacen la "forma estándar" no necesitaría ser inferido del contexto, lo cual resulta incompatible con el reclamo central de una concepción del lenguaje inspirada en un modelo de la performance, a saber: que lo puede llegar a contar como el significado de una emisión lingüística es algo que sólo puede reconocerse a partir de la concreta situación de habla en que la emisión en cuestión se halla situada.

\section{La taxonomía de las fuerzas ilocucionarias}

Para revisar más detalladamente en qué consiste exactamente la hipóstasis de la comunicación que encierra el proyecto habermasiano de una pragmática universal, puede ser relevante examinar su antecedente filosófico más directo, al menos en lo estrictamente relativo a la teorización de los actos de habla. Se trata de la particular concepción de John Searle. La versión de la teoría de los actos de habla elaborada por Searle representa una reformulación de la versión originariamente atribuible a John Austin, bosquejada en su muy influyente How to Do Things with Words. Tal como lo sugiere el título, lo que Austin intenta aquí es analizar en qué medida cabe reconocer que un hablante hace o realiza algo distintivo cuando dice algo en un determinado contexto. Más técnicamente, Austin sostiene que habría que diferenciar tres niveles de análisis: el nivel locucionario, el nivel ilocucionario y el nivel perlocucionario ${ }^{11}$. Por "acto locucionario" Austin entiende el acto por el cual el hablante dice algo susceptible de portar significado, en circunstancias que el significado de un acto locucionario resultaría ser una función de dos variables: su sentido y su referencia. Por "acto ilocucionario" Austin entiende el acto que un hablante realiza al decir lo que dice en el contexto adecuado, en circunstancias que la clase de acto así realizado se deja identificar en atención a una cierta fuerza distintiva.

\footnotetext{
${ }^{10}$ Habermas (1984), p. 359.

${ }^{11}$ Austin (1962), pp. 94-108.
} 
Así por ejemplo, al emitir la oración "mañana pasaré por aquí", el hablante puede estar efectuando una promesa, o quizá una amenaza. Y por "acto perlocucionario" Austin entiende, finalmente, la persecución de determinados efectos que la realización de un cierto acto ilocucionario puede tener en su destinatario, esto es, el oyente. Así, para seguir con el ejemplo, una amenaza puede tener un determinado efecto de intimidación en su destinatario, cuya producción, entonces, podría contar como el objetivo del eventual acto perlocucionario correspondiente.

La articulación de la teoría de los actos de habla propuesta por Searle puede ser entendida, según ya se sostuviera, como una reformulación de algunos de los hallazgos centrales de Austin. El quid se encuentra en la tesis de que al decir algo, bajo circunstancias apropiadas, el hablante siempre hace algo, esto es, realiza un determinado acto ilocucionario. Las variaciones fundamentales introducidas por Searle afectan los otros dos niveles identificados por Austin. De una parte, Searle prescinde de la noción de acto locucionario ${ }^{12}$, en vez de la cual propone hablar de "actos de emisión", cuyo análisis se reduciría a la identificación de la estructura de morfemas o grafemas de los cuales el hablante se vale para ejecutar un determinado acto ilocucionario. Los elementos que Austin entendía como constituyentes del significado, esto es, el sentido y la referencia de un determinado acto locucionario, pasan a ser entendidos como componentes dependientes, a modo de "actos proposicionales", del respectivo acto ilocucionario ${ }^{13}$. Y de este modo se hace explícita la "doble estructura del habla" que el propio Habermas tematiza recurriendo a la distinción searleana entre el contenido proposicional y la fuerza ilocucionaria de los actos de habla ${ }^{14}$.

De otra parte, Searle recomienda hablar de efectos, y no de actos, perlocucionarios, pues se trataría aquí de las consecuencias (contingentes) que un determinado acto ilocucionario puede producir en el oyente. Así, y en palabras del propio Habermas, lo que ha de ser diferenciado es, respectivamente, "decir algo; hacer algo diciendo algo; y causar algo mediante lo que se hace diciendo algo"15.

En este punto, cabe volver brevemente sobre la divergencia fundamental que, según Krämer, habría que reconocer entre las concep-

\footnotetext{
${ }^{12}$ Searle (1968), pp. 405-414.

${ }^{13}$ Searle (1969), pp. 22-32.

${ }^{14}$ Habermas (1984), pp. 404-409.

${ }^{15}$ Habermas (1999), p. 371.
} 
ciones de Austin y Searle. Pues a pesar de la evidente continuidad categorial que cabe advertir entre ambas, esa continuidad resulta en todo caso atravesada por el compromiso de Searle con la ontología dualista implicada en la distinción entre esquema y su instanciación, compromiso que, según Krämer, está completamente ausente en la propuesta de Austin. Esa divergencia radical se manifiesta nítidamente en la muy distinta pretensión clasificatoria que es posible atribuir a cada uno de ellos.

Austin propone una diferenciación de cinco clases de actos ilocucionarios, que como tales serían reconocibles en atención a su correspondiente fuerza pragmática distintiva, dejándose agrupar como sigue: actos "veredictivos", actos "ejercitivos", actos "compromisorios", actos "comportativos" y actos "expositivos"16. Lo importante aquí no es indagar en la naturaleza compartida por los actos de habla clasificados bajo cada una de estas cinco categorías, sino constatar, de entrada, que entre éstas no cabe reconocer una demarcación prístina. Pues como el propio Austin lo hace explícito, es enteramente posible que entre ellas se produzcan superposiciones, de modo tal que un concreto acto de habla pueda ser asignado a más de una de esas cinco categorías, las cuales, por lo mismo, no pueden ser entendidas como mutuamente excluyentes. Como ejemplo puede mencionarse aquí el tipo de acto de habla que consiste en dirigir un reproche a alguien. Según Austin, un acto de habla tal admite ser entendido tanto al modo de un acto "veredictivo" como al modo de un acto "comportativo", según cuál sea el punto de vista determinante. $\mathrm{Al}$ dirigir un reproche a otra persona, el hablante en todo caso pretende hacer responsable a esa persona de algo que ha hecho o dejado de hacer, en lo cual se haría manifiesta la fuerza ilocucionaria que caracteriza a los "veredictivos"17. Pero al hacer eso, el hablante típicamente también pone de manifiesto una cierta respuesta emocional al comportamiento ajeno - lo cual supone la adopción de lo que Strawson llamaría una actitud reactiva-, siendo esto último el criterio de reconocimiento de la realización de un acto "comportativo"18.

Lo anterior sugiere, más allá de cuáles sean los méritos o deméritos de la clasificación propuesta por Austin, que ésta se halla lejos de cualquier pretensión taxonómica estricta. Su inspiración, podría uno

${ }^{16}$ Austin (1962), pp. 148-164.

${ }^{17}$ Ibídem, p. 155.

18 Ibídem, p. 160. Un análisis de esta bivalencia del reproche, en pos del desarrollo de una teoría comunicativa de la función de la pena, se encuentra en Mañalich (2007), pp. 156-161. 
decir, es ante todo didáctica. De ahí que el propio Austin sostuviera que él mismo no quedaba muy satisfecho con la diferenciación de esas cinco clases de ilocuciones, la cual de ninguna manera pretendía ser definitiva $^{19}$. Su propósito, por lo demás, apuntaba a la necesidad de problematizar, en los propios términos de Austin, dos fetiches filosóficos: el binomio verdadero/falso y el binomio hecho/valor ${ }^{20}$.

La situación es distinta frente a la propuesta clasificatoria de Searle, la cual exhibe una pretensión taxonómica inusitadamente fuerte, tal como ella es anunciada en la introducción a su volumen Expression and Meaning. Desautorizando el dictum de Wittgenstein, según el cual los posibles usos del lenguaje serían — literalmente - "incontables" 21 , Searle se pregunta por qué habría que suponer que el lenguaje pudiera ser más refractario a la clasificación exacta que cualquier otro aspecto de la vida social de los miembros de la especie humana. Su respuesta reza como sigue: "si tomamos el acto ilocucionario [...] como la unidad de análisis [...], entonces encontramos que hay cinco maneras generales de usar el lenguaje, cinco categorías generales de actos ilocucionarios" 22 . Estas cinco categorías serían la de los actos "asertivos", la de los "compromisorios", la de los "directivos", la de los "expresivos" y la de los "declarativos", cuya diferenciación precisa resultaría de la aplicación de doce criterios clasificatorios. Aquí sólo es posible detenerse en los dos primeros criterios. El primero, y más importante, en palabras del propio Searle, consiste en la identificación del "punto" o "propósito" ilocucionario: aquello de cuya realización se trata en la ejecución de un determinado acto de habla ${ }^{23}$. El segundo criterio sería la dirección de ajuste entre palabras y mundo: el punto o propósito ilocucionario de determinados tipos de actos de habla consistiría en lograr que el contenido proposicional de las palabras empleadas se adapte al mundo; otros tipos de actos de habla, en cambio, tendrían como propósito que el mundo se adapte a la dirección de las palabras ${ }^{24}$. Así, mientras que la relación de ajuste propia de un acto asertivo sería de adaptación de las palabras al mundo ${ }^{25}$, la relación de ajuste propia tanto

\footnotetext{
${ }^{19}$ Austin (1962), p. 152.

${ }^{20}$ Ibídem, p. 151.

${ }^{21}$ Wittgenstein (1984b), § 23.

${ }^{22}$ Searle (1979), pp. vii-viii.

${ }^{23}$ Ibídem, pp. 2-3.

${ }^{24}$ Ibídem, pp. 3-4.

${ }^{25}$ Ibídem, p. 12.
} 
de un acto directivo como de un acto compromisorio sería la inversa, esto es, de adaptación del mundo a las palabras ${ }^{26}$. En los actos expresivos, por su parte, no cabría reconocer tal relación de ajuste ${ }^{27}$, mientras que en los actos declarativos, finalmente, se darían ambas relaciones de adaptación simultáneamente ${ }^{28}$.

Lo importante aquí es enfatizar la manera en que Searle pretende dar por concluida su empresa taxonómica, a saber: sosteniendo —en la forma de un acto de habla asertivo - que no hay un número infinito de usos posibles del lenguaje, sino sólo cinco. Cuando hablamos, no hay más que cinco cosas que podemos estar haciendo: les decimos a otros cómo son las cosas, o intentamos que hagan determinadas cosas, o nos comprometemos nosotros mismos a hacerlas, o expresamos nuestros sentimientos, o bien producimos ciertos cambios a través de determinadas declaraciones ${ }^{29}$.

Esta insistencia de Searle en distanciarse de la observación de Wittgenstein acerca de la incontable variedad de posibles usos del lenguaje es de extrema importancia para lo que interesa en el contexto de este trabajo. Pues el programa habermasiano de una pragmática universal se encuentra indisolublemente ligado a la pretensión clasificatoria que inspira la versión de teoría de los actos de habla desarrollada por Searle. Y como habrá de mostrarse todavía, el punto neurálgico aquí está representado por la peculiar función atribuida al concepto de (seguir una) regla, que se aleja - y de una manera nada marginal — de la función que ese concepto desempeña en la filosofía tardía de Wittgenstein.

\section{Entendimiento y pretensiones de validez}

Para seguir indagando en las implicaciones del programa habermasiano de una pragmática universal que lo comprometen con lo que Krämer llamara el modelo de los dos mundos, es imprescindible clarificar ahora el modo en que Habermas intenta perfilar las bases lingüístico-pragmáticas de la acción comunicativa, esto es, de la acción orientada al entendimiento. Habermas se vale aquí de una cierta

\footnotetext{
${ }^{26}$ Ibídem, p. 14.

${ }^{27}$ Ibídem, p. 15.

${ }^{28}$ Ibídem, pp. 18-19.

${ }^{29}$ Ibídem, p. 29.
} 
reformulación del análisis de las fuerzas ilocucionarias emprendido por Searle, sometiéndolo a una revisión pormenorizada. A este respecto, Habermas se reconoce como un continuador en la elaboración de una teoría de los actos de habla que pretende reconstruir el sistema elemental de reglas que un hablante competente ha de dominar, al modo de un know how, para poder emitir oraciones de modo comunicativamente exitoso. La capacidad de desempeñarse como un hablante competente equivale, en estos términos, a disponer de una competencia relativa a la aplicación de reglas pragmáticas, esto es, de reglas que fijan condiciones necesarias y suficientes para que la emisión de una determinada oración, en un determinado contexto, cuente como la realización de un correspondiente acto ilocucionario ${ }^{30}$.

En esta tematización de semejante competencia lingüísticopragmática relativa a la aplicación de reglas, Habermas ofrece una definición de lo que cabe entender por tales reglas pragmáticas: se trata de reglas que configuran la infraestructura misma de las posibles situaciones de habla ${ }^{31}$. Así se hace patente el compromiso de Habermas con el postulado searleano según el cual hablar equivale a "realizar actos de conformidad con reglas" 32 . Y Searle especifica qué quiere decir esto último en términos de que "la estructura semántica de un lenguaje puede ser considerada como una realización convencional de una serie de conjuntos de reglas constitutivas subyacentes", de modo tal que "los actos de habla son actos característicamente realizados a través de la emisión de expresiones con arreglo a estas reglas constitutivas" 33 .

Que Searle hable aquí de reglas semánticas, y no de reglas pragmáticas como lo hace Habermas, no debe generar la impresión de que tras la divergencia terminología se esconda una divergencia conceptual relevante. Pues para Searle el acto ilocucionario es la unidad mínima de significado — que es aquello de lo cual se ocupa la semántica—, lo cual quiere decir, entonces, que la respectiva fuerza ilocucionaria es determinante para el significado de tal acto, siendo esto último explícitamente validado por Habermas ${ }^{34}$.

Que estas reglas sean entendidas como reglas constitutivas quiere decir, ahora bien, que ellas representan la condición de posibilidad

\footnotetext{
${ }^{30}$ Habermas (1984), pp. 386-387.

${ }^{31}$ Ibídem, p. 387.

${ }^{32}$ Searle (1969), pp. 36-37.

${ }^{33}$ Ibídem, p. 37.

${ }^{34}$ Habermas (1984), pp. 409-417.
} 
de que a través de una determinada emisión (oral o escrita) de palabras tenga lugar la realización de un determinado acto ilocucionario ${ }^{35}$. Como lo explica Searle, se trata de "reglas para el uso del dispositivo indicativo de la fuerza ilocucionaria" del respectivo acto de habla ${ }^{36}$. Esto vale, en todo caso, para lo que el propio Searle denomina la "regla esencial", esto es, la regla de conformidad con la cual la emisión de una determinada expresión cuenta como la realización del acto ilocucionario correspondiente. En el caso de una promesa, esto es, de un acto compromisorio, por ejemplo, la regla esencial sería aquella de conformidad con la cual la emisión de una expresión del tipo "yo te prometo que haré X" cuente como la asunción, por parte del hablante, de una obligación de hacer $\mathrm{X}^{37}$.

No es posible detenerse aquí en las muy significativas variaciones que Habermas introduce respecto de esta postulación de un conjunto de reglas constitutivas cuya satisfacción sería presupuesto de la realización de determinados actos ilocucionarios. Lo fundamental es advertir que el hallazgo central es conservado. La capacidad de proferir exitosamente emisiones que cuenten como la realización de determinados actos de habla identificables en atención a su respectiva fuerza ilocucionaria - esto es, la competencia necesaria para la performance correspondiente-, sería en todo caso una capacidad que se deja explicar como un dominio (práctico) de reglas compartidas. Y en términos de Habermas, se trata aquí de una competencia para el empleo de oraciones a través de cuya emisión pueden verse realizadas las tres funciones pragmáticas generales del lenguaje: la representación de estados de cosas, la auto-representación y la creación de vínculos interpersonales ${ }^{38}$.

Sobre esta base resulta posible volver sobre la definición del concepto de acción comunicativa. Según ya se observara, Habermas entiende por esto lo que él mismo llama una "acción orientada al entendimiento". Ahora es posible considerar la definición más precisa que el propio Habermas ofrece. Por "acción comunicativa" habría que entender "aquellas interacciones mediadas lingüísticamente en que todos los participantes persiguen con sus actos de habla fines ilocucionarios y

\footnotetext{
${ }^{35}$ Searle (1969), pp. 33-42. Véase también Searle (1995), pp. 27-29, 43-51.

${ }^{36}$ Searle (1969), pp. $62-64$.

${ }^{37}$ Ibídem, p. 63.

${ }^{38}$ Habermas (1984), p. 390.
} 
sólo fines ilocucionarios" ${ }^{\prime 39}$. Dado que el criterio de reconocimiento de una instancia de acción comunicativa consiste en su exclusiva orientación al entendimiento, lo decisivo resulta ser la determinación de "qué significa entender una oración empleada comunicativamente" 40 . Y es aquí donde aparece la muy importante conexión entre significado y validez como nota distintiva del programa de una pragmática universal. Pues Habermas sostiene que un acto de habla es entendido por su destinatario cuando éste reconoce sus específicas condiciones de aceptabili$\mathrm{dad}^{41}$, esto es, las condiciones que lo hacen aceptable, de modo tal que el oyente pueda tomar posición, de aceptación o de rechazo, frente a la pretensión de validez entablada por el hablante, siendo posible entonces que ambos alcancen un acuerdo acerca de "las obligaciones relevantes para la interacción posterior" ${ }^{\prime 2}$. Y esto se sigue de que, para Habermas, la fuerza ilocucionaria de un acto de habla aceptable consiste en que ella puede llevar al oyente a dejarse confiar en el cumplimiento de las obligaciones típicas que el hablante contrae al entablar una determinada pretensión de validez ${ }^{43}$.

De esta manera, Habermas puede proponer una nueva clasificación de tipos puros de actos ilocucionarios, precisamente en atención a la específica pretensión de validez abiertamente entablada por el hablante, en la medida en que su acto de habla asuma la correspondiente "forma estándar". Y no es casualidad, entonces, que los tipos puros de actos de habla orientados al entendimiento se correspondan estrictamente con las tres funciones pragmáticas generales que Habermas atribuye al lenguaje: (1) una función de representación de estados de cosas, que se realiza a través de actos de habla constatativos, cuya fuerza ilocucionaria específica se identifica por la pretensión de verdad que el hablante entabla para el contenido proposicional del acto; (2) una función de auto-representación, que se realiza a través de actos de habla expresivos, cuya fuerza ilocucionaria específica se identifica por la pretensión de sinceridad que el hablante reclama para lo que dice de sí mismo; y (3) una función de constitución de vínculos intersubjetivos, que se realiza a través de actos de habla regulativos, cuya fuerza ilocucionaria específi-

\footnotetext{
${ }^{39}$ Habermas (1999), p. 378.

${ }^{40}$ Ibídem, p. 381.

${ }^{41}$ Ibídem, p. 382.

${ }^{42}$ Ibídem.

${ }^{43}$ Habermas (1984), p. 432.
} 
ca se identifica por la pretensión de rectitud o corrección normativa que el hablante reclama para determinadas expectativas de acción ${ }^{44}$.

Ahora es posible retomar el análisis de la conexión que existiría entre reglas pragmáticas y fuerzas ilocucionarias. Habermas sostiene que la fuerza pragmática propia de un determinado acto ilocucionario sólo se dejaría explicar por referencia a aquellos presupuestos específicos que Searle tematiza a través de lo que él llama la "regla esencial"45. Pues como afirma el propio Habermas, lo que se expresa en la articulación de tal regla esencial sería que el éxito ilocucionario de un acto de habla depende de que el hablante asuma un determinado compromiso en el cual el oyente pueda hacer descansar su confianza: "una emisión puede contar como una promesa, una afirmación, una solicitud o una pregunta si y sólo si el hablante hace una oferta que él, una vez que el oyente la acepte, está dispuesto a cumplir"46. Y es así que el hablante contrae las obligaciones correspondientes a las respectivas pretensiones de validez por él entabladas: una obligación de fundamentación relativa al desempeño de una pretensión de verdad; una obligación de confirmación (conductual) relativa al desempeño de una pretensión de sinceridad; y una obligación de justificación relativa al desempeño de una pretensión de rectitud o corrección normativa ${ }^{47}$.

En atención a la sola terminología aquí empleada, tendría que resultar suficientemente claro en qué medida el programa habermasiano de una pragmática universal entraña una fuertísima disposición a la "juridificación" de las condiciones del entendimiento. Pues según Habermas, lo que hace el autor de un acto de habla que busca entenderse con otro sería, en lo fundamental, esgrimir determinadas pretensiones de validez, ofreciendo una garantía del cumplimiento futuro de las correspondientes obligaciones de desempeño.

\section{Reglas, convenciones y la autonomía del significado}

Habermas conceptúa el entendimiento como la obtención de un acuerdo entre sujetos lingüísticamente competentes, en circunstancias

${ }^{44}$ Habermas (1999), pp. 391-396. Además de estas tres pretensiones de validez, cada una de las cuales determina la fuerza ilocucionaria específica de un tipo puro de acto de habla orientado al entendimiento, Habermas da cuenta de la pretensión de inteligibilidad que sería común a todo acto de habla ilocucionario.

${ }^{45}$ Habermas (1984), p. 430.

${ }^{46}$ Ibídem, p. 431.

${ }^{47}$ Ibídem, pp. 433-434. 
que esta competencia lingüística sería una función del dominio implícito - en términos de un know how - de reglas pragmáticas universales. En este sentido, Habermas aparece como un genuino heredero de la tesis searleana según la cual hablar sería, ante todo, un asunto de ejecutar determinadas acciones con arreglo a un determinado set de reglas. A través del recurso a lo que él llama "reglas constitutivas", Searle pretende esclarecer la ontología de los actos ilocucionarios en tanto hechos institucionales. Para la realización exitosa de una promesa, por ejemplo, sería necesario que la respectiva emisión del hablante satisfaga una serie de condiciones fijadas en reglas, de conformidad con las cuales se constituiría, entonces, la correspondiente obligación del hablante, que en tal medida se constituye en promitente. En los términos de Habermas, para ello es necesario que la emisión satisfaga las condiciones que hacen reconocible la correspondiente obligación que asume el hablante de desempeñar la respectiva pretensión de validez.

Esta concepción de la ontología de los actos ilocucionarios supone, como Searle mismo lo hace explícito, que una cierta dependenciade-reglas contaría como propiedad distintiva del lenguaje. Pues es un hecho, piensa Searle, que "en general los actos ilocucionarios son realizados al interior del lenguaje en virtud de ciertas reglas, y en efecto no podrían ser realizados si el lenguaje no permitiera la posibilidad de su realización" 48 .

Esta última proposición admite ser puesta radicalmente en cuestión, lo cual exige, sin embargo, hacerse cargo de un muy difundido lugar común. A partir de la obra tardía de Wittgenstein, es usual que las semánticas (o teorías del significado) adscritas a la tradición analítica reconozcan una fuerte relación entre reglas y significado. Mas sería apresurado asumir, sin más, que para Wittgenstein tuviese sentido entender el habla como una actividad gobernada por reglas ${ }^{49}$. En palabras de Krämer:

No hablamos como hablamos porque al hablar sigamos reglas. Las reglas no son un elemento determinante del uso del lenguaje que después, en el marco de una teoría del lenguaje reconstructiva de reglas, pudiera asumir una función explicativa del lenguaje $e^{50}$.

\footnotetext{
${ }^{48}$ Searle (1969), p. 38.

${ }^{49}$ Véase Wittgenstein (1984b), $\S \S 80,84$.

${ }^{50}$ Krämer (2001), p. 125. Véase también Wellmer (2004), pp. 58-59, 65-71.
} 
Esto resulta del hecho de que las reglas jamás son preexistentes a los juegos de lenguaje por referencia a los cuales podemos describir - pero no explicar - lo que significan determinadas palabras empleadas bajo determinadas circunstancias. Esto no quiere decir, ciertamente, que no existan condiciones necesarias para la realización de un determinado acto ilocucionario. La pregunta decisiva es, más bien, si tales condiciones pueden entenderse fijadas por (y en) reglas, que es, sin embargo, lo que Searle postula en la forma de una "regla esencial". Pues esta regla esencial se expresaría, precisamente, en un determinado dispositivo convencional que serviría de indicador de la respectiva fuerza ilocucionaria del acto de habla correspondiente, al menos en su versión estándar - por ejemplo, la primera persona del modo indicativo de un verbo explícitamente performativo, a través de cuyo empleo el hablante realizaría, entonces, el correspondiente acto ilocucionario ("yo prometo que...").

En este punto, puede ser de interés dirigir la mirada a la revisión crítica de la posibilidad de una fijación convencional de la fuerza ilocucionaria de los actos de habla, ofrecida por Donald Davidson, quien junto a Austin - y a diferencia de Searle y Habermas - cuenta como uno de los exponentes de un rechazo a lo que Krämer llama el modelo de los dos mundos. Ciertamente, Davidson no niega que determinados dispositivos convencionales puedan contribuir a la determinación de la fuerza ilocucionaria de una emisión lingüística. El punto es que no es posible reconocer algo así como una conexión necesaria. Pues nadie pondría en duda que la emisión de una misma oración en el modo indicativo puede contar sin más como la realización de una pregunta, cuyo indicador convencional tendría que consistir en el uso del modo interrogativo, o como la impartición de una orden, cuyo indicador convencional tendría que consistir en el uso del modo imperativo.

De acuerdo con Davidson, el uso de un modo gramatical distinto del indicativo se deja entender en términos de la designación de una determinada fuerza ilocucionaria relativa a una oración formulada, a su vez, en el modo indicativo ${ }^{51}$. De esta manera resulta posible analizar la emisión de una oración no-indicativa mediante su descomposición en dos actos de habla diferenciados, a saber: la emisión de una determinada oración en el modo indicativo y la emisión de una correspondiente

${ }^{51}$ Davidson (2001a), pp. 119-121. 
fuerza ilocucionaria, designada por el indicador del modo no-indicativo correspondiente. Así, uno podría analizar la emisión de la oración interrogativa "¿está Pedro ahí?" descomponiéndola en la emisión de la oración indicativa "Pedro está ahí" 52 , de una parte, y la emisión que señala la fuerza interrogativa referida a esa oración indicativa, de otra, sin que quepa reconocer, empero, la emisión de una conjunción de ambas emisiones. Esto es de relevancia, porque entonces cabe sostener que a pesar de que la emisión de la oración interrogativa, como tal, carece de valor de verdad, las dos emisiones en que puede descomponérsela para efectos del análisis sí tienen condiciones de verdad, y esto significa: condiciones de verdad que son independientes entre sí. Puesto que la indicación de la fuerza ilocucionaria a través del correspondiente modo gramatical es de naturaleza puramente convencional, sin embargo, esta indicación de la fuerza ilocucionaria puede ser falsa. Lo cual significa, a su vez, que la emisión de la oración no-indicativa puede, de hecho, exhibir una fuerza ilocucionaria distinta de aquella que es designada por el respectivo indicador de modo ${ }^{53}$.

Lo crucial de esta maniobra se encuentra en que de esta manera se hace reconocible lo que Davidson denomina el "principio de la autonomía del significado", con arreglo al cual el significado y la fuerza de una expresión son siempre potencialmente independientes de cualquier dispositivo convencional para la identificación de sus propiedades semánticas y pragmáticas. Lo cual incluso valdría, según ya se sugiriera, tratándose (del uso) de lo que Austin llamara "verbos explícitamente performativos" $" 54$.

Hasta aquí, no obstante, el argumento de Davidson no alcanza a refutar la tesis de Searle, ya que éste no afirma, de hecho, la existencia de una relación puramente convencional entre el modo gramatical de una oración y la fuerza ilocucionaria de su emisión ${ }^{55}$. Searle entiende,

52 El modo indicativo de esta oración cuenta, a su vez, como designación de una fuerza ilocucionaria distintiva, a saber, la de la afirmación. Al respecto Tugendhat (1976), p. 64.

${ }^{53}$ Davidson (2001a), p. 121.

${ }^{54}$ Ibídem, pp. 117-120. Un ejemplo de un verbo explícitamente performativo es "prometer". Quien dice "yo (te) prometo que ..." hace explícito lo que hace al decir lo que dice a través del uso de ese verbo. El argumento de Davidson pretende mostrar que incluso en tal caso la fuerza pragmática de la emisión de la oración no alcanza a ser prejuzgado por ese mismo "indicador convencional".

${ }^{55}$ Searle (1969), pp. 36-40. 
más bien, que determinadas convenciones pueden contar como manifestación o realización de las reglas constitutivas de las cuales dependería, ontológicamente, la posibilidad de la fuerza ilocucionaria de determinados actos de habla ${ }^{56}$. Ante esto, lo fundamental del principio de la autonomía del significado de Davidson se halla en su incompatibilidad con la idea de que desempeñarse como un hablante competente pudiese depender de la satisfacción de condiciones fijadas en reglas universales, compartidas con quienes pueden aparecer como interlocutores ${ }^{57}$. Y esto resulta del hecho de que, según Davidson, para que haya entendimiento entre hablante y oyente no es necesario en absoluto que las palabras que cada uno emplea al decir algo signifiquen lo mismo. A este respecto, la divergencia entre Davidson y Habermas no podría ser mayor, dado que este último sostiene que la asignación de idéntico significado a una misma emisión lingüística cuenta como condición mínima de todo entendimiento posible ${ }^{58}$.

\section{La caridad de la interpretación}

De conformidad con lo anterior, una falta de coincidencia en la atribución previa de significado a determinadas expresiones no obsta, según Davidson, a la posibilidad de un entendimiento recíproco, porque lo que convierte a un sujeto en un hablante competente es nada más y nada menos que una disposición a producir una correcta interpretación de palabras que no han sido oídas con anterioridad, o bien que no han sido oídas portando el significado que el hablante ahora les atribuye ${ }^{59}$. Davidson desarrolla esta tesis de la mano de su célebre teoría de la interpretación radical, con arreglo a la cual no resulta posible reconocer algo así como una garantía de entendimiento recíproco que pudiera ser anterior a la efectiva comunicación (exitosa) entre hablante y oyente - esto es, entre hablante e intérprete ${ }^{60}$.

La (potencial) radicalidad de toda situación de interpretación se sigue, justamente, de la imposibilidad de una garantía previa de enten-

${ }^{56}$ Ibídem, pp. 40-41.

${ }^{57}$ Véase Davidson (2005), pp. 109-125.

${ }^{58}$ Habermas (1999), p. 393: "El término "entendimiento"” tiene el significado mínimo de que (a lo menos) dos sujetos lingüística e interactivamente competentes entienden idénticamente una expresión lingüística”.

${ }^{59}$ Davidson (2001a), p. 277.

${ }^{60}$ Ibídem, pp. 125-128. 
dimiento entre hablante e intérprete, lo cual trae consigo una condición de irreductible indeterminación. Y esto, con independencia de que se trate de una situación de interpretación entre quienes hablan una misma lengua materna o no. Pues distintivo de toda situación de interpretación es precisamente la pregunta de si hablante e intérprete hablan un mismo lenguaje ${ }^{61}$. La indeterminación de la interpretación, que se traduce en la inexistencia de una garantía pre-comunicativa de la corrección de atribución de significado, por parte del intérprete, a las expresiones del hablante, sólo logra reducirse - mas nunca eliminarse del todo- en la medida en que el intérprete recurre a ciertos estándares que maximizan la posibilidad de una atribución de significado consistente. Y estos estándares se dejan entender al modo de una hipótesis de cierto grado de racionalidad — esto es, de coherencia y correspondencia — en el hablante, bajo la cual el intérprete procede a atribuir, provisionalmente, significado a las expresiones del hablante, en el sentido de lo que Davidson denomina el "principio de caridad"62.

Este principio hermenéutico funciona al modo de un procedimiento de adaptación racional. La interpretación exige una toma de posición caritativa, esto es, generosa para con aquel cuyas emisiones son objeto de interpretación, de manera de maximizar (racionalmente) su carácter significativo ${ }^{63}$. A este respecto, Davidson modela la atribución de significado a las emisiones del hablante en términos de una semántica veritativa, inspirada en la definición semántica del predicado "verdad" propuesta por Tarski ${ }^{64}$. Esto quiere decir que la atribución de significado ha de operar por la vía de la identificación de las condiciones de verdad de las emisiones del hablante, lo cual se deja explicitar a través de una reformulación recursiva de la oración emitida por el hablante en una correspondiente oración metalingüística, donde la formulación entre comillas de la oración del hablante cuenta como el nombre de esa oración en tanto sujeto gramatical de la correspondiente oración meta-lingüística que identifica las condiciones de verdad de la primera a través de la correspondiente supresión de las comillas. Por ejemplo:

${ }^{61}$ Ibídem, p. 125.

${ }^{62}$ Ibídem, pp. 136-139.

${ }^{63}$ Véase Davidson (2004), pp. 35-37.

${ }^{64}$ Aquí hay que observar, sin embargo, que mientras para Tarski se trata de la definición del predicado "verdad" al interior de un determinado lenguaje (formalizado), para Davidson se trata de la determinación del significado de cualquier oración de un determinado lenguaje (natural) en atención a sus condiciones de verdad. 
"La nieve es blanca" es verdad si y sólo si la nieve es blanca.

Por supuesto, así planteada, la operación se traduce en un mero "desencomillamiento". El punto es, sin embargo, que de ese modo resulta abierta la vía para un holismo semántico, por oposición a un atomismo semántico ${ }^{65}$. Pues una teoría veritativa del significado tal funciona "relacionando las condiciones de verdad, ya conocidas, de cada oración con aquellos aspectos ('palabras') de la oración [en cuestión] que se repiten en otras oraciones y a los cuales pueden asignarse roles idénticos en otras oraciones" ${ }^{\circ 6}$. Observa Davidson:

[s]i el significado de las oraciones es dependiente de su estructura, y si entendemos el significado de cada ítem de su estructura solamente como abstracción de la totalidad de las oraciones en las cuales aquél figura, entonces sólo podemos determinar el significado de una oración (o palabra) cualquiera determinando el significado de toda oración (y palabra) en ese lenguaje $\mathrm{e}^{67}$.

Y en esto, Davidson ciertamente no está solo. Pues ya Wittgenstein observaba que "entender una oración significa entender [todo] un lenguaje" 68 .

El recurso a un holismo semántico da cuenta de la potencial indeterminación de toda interpretación. Pues ello supone que siempre puede haber más de una alternativa interpretativa que haga posible una atribución consistente de significado a las emisiones de un hablante. No existe algo así como un punto de vista apriorístico, entonces, para el juzgamiento de la interpretación como satisfactoria o insatisfactoria. Y esto quiere decir, a su vez, que la competencia para el entendimiento lingüístico no puede ser reducida al dominio (práctico) de un determinado conjunto de reglas ${ }^{69}$. El entendimiento sólo depende, antes bien,

${ }^{65}$ La divergencia afecta la pregunta por la unidad mínima del significado lingüístico. Tradicionalmente, las concepciones atomistas favorecen la idea de que es cada palabra, cada término aisladamente considerado, lo que porta significado. Las formas más radicales de holismo semántico, como el de Davidson, favorecen la idea de que es recién en la totalidad de un lenguaje que emerge el significado.

${ }^{66}$ Davidson (2001a), p. 25.

${ }^{67}$ Ibídem, p. 22.

${ }^{68}$ Wittgenstein (1984b), § 199. Acerca de esta coincidencia entre Wittgenstein y Davidson a favor de un holismo semántico, véase Rorty (1979), pp. 301-305; Wellmer (2004), pp. 27-28, 46-47, 120-165.

${ }^{69}$ Krämer (2001), p. 191. 
de que el hablante ofrezca suficientes puntos de apoyo para que el intérprete pueda producir una interpretación satisfactoria de sus emisiones. Y ningún dispositivo convencional puede representar una condición necesaria de la comunicación, o bien un presupuesto de "la existencia de un lenguaje". Si el lenguaje tiene algo de convencional, esto se reduce, apunta Davidson, a que las personas de hecho tienden a hablar parecido a como lo hacen sus vecinos ${ }^{70}$.

Es importante aquí dar cuenta de que esta modelación de las condiciones del entendimiento, en términos de una teoría de la interpretación radical, ha sido criticada por Habermas ${ }^{71}$. Según éste, Davidson situaría al intérprete "en el papel de un teórico que procede empíricamente, que efectúa observaciones del comportamiento de una cultura ajena y que [...] busca una explicación nomológica para el incomprensible comportamiento lingüístico de los "nativos"'72. Este cientificismo atribuido a Davidson, quien partiría del "solipsismo metodológico del observador aislado"73, lleva a Habermas a calificar el programa de la teoría de la interpretación radical como una propuesta de eliminación de la categoría "significado" 74 .

La lectura habermasiana de Davidson representa un buen ejemplo de una interpretación que no cultiva la actitud de acomodación racional que caracteriza la adopción del principio de caridad. Pues Davidson es explícito, en primer término, en lo relativo a la posición del intérprete: "el punto no es que el hablante u oyente tenga una teoría, sino que hablen y entiendan con arreglo a una teoría - una teoría que es necesaria sólo cuando queremos describir sus habilidades y performances"75. El solipsismo metodológico del lingüista que estudia empíricamente el habla de una comunidad de nativos podrá servir para caracterizar el proyecto quineano de una teoría de la traducción radical, tal como éste se halla trazado en Word and Object, pero no sirve para caracterizar la noción de interpretación empleada por Davidson. Pues éste, a diferencia de Quine, no muestra escrúpulo ontológico alguno frente a la postulación del significado como entidad intensional

\footnotetext{
${ }^{70}$ Davidson (2001a), p. 278.

${ }^{71}$ Habermas (2003), pp. 66-80.

72 Ibídem, p. 67.

${ }^{73}$ Ibídem, p. 77.

${ }^{74}$ Ibídem, p. 67.

${ }^{75}$ Davidson (2005), p. 113.
} 
$(=\text { no-extensional })^{76}$. Según Davidson, la razón para la articulación de una semántica veritativa - esto es, de una teoría del significado que pretende identificar el "significado literal" de la emisión de una oración en atención a sus condiciones de verdad - no responde al pathos de un materialismo eliminativo ${ }^{77}$, sino a la sola circunstancia de que la categoría "significado" no ofrece un buen punto de partida para explicar lo que es el significado ${ }^{78}$.

Desde este punto de vista, la insistencia de Habermas en entender monolíticamente el programa de una semántica veritativa que iría desde Frege y el primer Wittgenstein, pasando por Carnap y Quine, hasta Davidson $^{79}$, resulta ser, usando la terminología del propio Habermas, demasiado "desdiferenciada". Pues ello desconoce que el programa davidsoniano de una semántica veritativa, a diferencia de lo que cabe decir de los programas de Carnap y Quine, representa un intento por articular una concepción radicalmente no-epistémica del significado. Como apunta Rorty, para Davidson "la cuestión de 'cómo funciona el lenguaje' no tiene ninguna conexión especial con la cuestión de 'cómo funciona el conocimiento" $" 80$.

${ }^{76}$ Una entidad es extensional si sus relaciones de identidad se conservan a través de sus diferentes descripciones posibles, para lo cual el método estándar es el de la sustitución salva veritate. Así, la verdad de la oración "Bruto mató a Julio César" implica la verdad de la oración "Bruto mató al mejor amigo de Marco Antonio" (en la medida en que, de hecho, Julio César haya sido el mejor amigo de Marco Antonio). Una entidad es intensional, en cambio, si sus relaciones de identidad varían según cuál sea la descripción escogida. Así, la verdad de la oración "Cleopatra sabe que Bruto mató a Julio César" no implica la verdad de la oración "Cleopatra sabe que Bruto mató al mejor amigo de Marco Antonio", porque el uso del verbo "saber" transforma el respectivo contexto en uno intensional.

77 Como sí en Quine. Véase Quine (1960), pp. 191-211. Por “materialismo eliminativo" se entiende (en el contexto de la filosofía de la mente) la concepción según la cual cabría suprimir o eliminar el vocabulario relativo a "lo mental", en la medida en que su rendimiento explicativo de los fenómenos correspondientes se vuelva superfluo ante la disponibilidad de explicaciones alternativas formuladas en vocabulario puramente materialista o "fisicalista". Véase Churchland (1999), pp. 75-85. Tal estrategia de eliminación tiende a estar dirigida a entidades intensionales (tales como "significados", "proposiciones", etc.) A diferencia de las distintas variantes de "monismo reduccionista", sin embargo, el materialismo eliminativo niega la posibilidad de reducir el vocabulario de lo mental al vocabulario "fisicalista".

${ }^{78}$ Davidson (2001a), pp. 20-21.

${ }^{79}$ Véase Habermas (1999), pp. 355-356.

${ }^{80}$ Rorty (1979), p. 259. 
Lo anterior tendría que conducir a que la estrategia de acudir a la perspectiva de la tercera persona para elaborar una teoría del significado aparezca bajo una luz algo distinta. Según Davidson, la razón por la cual resulta necesario acudir a la perspectiva de la tercera persona - esto es, a la perspectiva del observador-, que es lo que trae consigo el recurso a la imagen de la triangulación (entre hablante, intérprete y mundo), se encuentra en que es recién la triangulación lo que hace posible que emerja la posibilidad del error, es decir, que emerja la objetividad. La teoría de la interpretación radical pretende explicar cómo es posible que una persona llegue a entender lo que dice otra, siendo esta habilidad determinante para nuestro sentido del mundo como independiente de nosotros mismos, y con ello determinante para la posibilidad misma del pensamiento ${ }^{81}$. Pues como dice Davidson: "La aproximación en tercera persona es tuya y mía" ${ }^{\prime 2}$.

\section{El carácter público del lenguaje}

El análisis precedente se ha centrado en poner de manifiesto la hipóstasis en que se traduce la comprensión del lenguaje como estructura de reglas constitutivas cuyo dominio confiere una competencia específica $^{83}$. El desarrollo consecuente de la premisa implicada en esa hipóstasis tiene que llevar, como Searle no duda en hacerlo explícito, a la tesis de que el lenguaje, en sí mismo, estaría diseñado como "una categoría auto-identificativa de hechos institucionales" 84 . Pero los hechos institucionales, como bien lo sabe Searle, dependen de convenciones. Y no puede haber convenciones sin que ya haya lenguaje, porque toda convención se halla lingüísticamente articulada. Como observa Davidson, disponer de un lenguaje es condición necesaria de la posibilidad de disponer de convenciones ${ }^{85}$.

El problema, ahora bien, es que el rechazo a la adopción de la ontología de los dos mundos lleva a Davidson a sostener, provocativamente, que no existe tal cosa como "el lenguaje"; al menos si por "lenguaje"

\footnotetext{
${ }^{81}$ Davidson (2004), p. 143.

${ }^{82}$ Ibídem.

${ }^{83}$ Véase Davidson (2005), pp. 89-107.

${ }^{84}$ Searle (1995), p. 73.

${ }^{85}$ Davidson (2001a), p. 280.
} 
se entiende, agrega Davidson, aquello que algunos filósofos y lingüistas parecen entender por "lenguaje" ${ }^{86}$. Y esto, porque la posibilidad de una interpretación satisfactoria de las emisiones de un hablante no depende de que hablante e intérprete atribuyan, de antemano, idéntico significado a las expresiones empleadas por el primero. De ahí que Davidson observe que cada hablante puede hablar su propio idioma, sin que esto obste a la comunicación, siempre que cada oyente, en tanto intérprete, de hecho entienda (o llegue a entender) a su interlocutor ${ }^{87}$.

Esto último resulta ser de la mayor importancia, puesto que la idea de que es posible que cada interlocutor hable su propio lenguaje parecería desafiar el hallazgo de Wittgenstein en cuanto a la imposibilidad de un lenguaje auténticamente privado ${ }^{88}$. Y a este respecto, una concepción searleana o habermasiana parece tener la ventaja inequívoca de volver auto-evidente el carácter público del lenguaje, esto es, precisamente mediante la tesis de que el desempeño de una persona como hablante competente dependería del dominio práctico de un conjunto de reglas pragmáticas universales. Pero esta aparente ventaja comparativa del modelo de los dos mundos está lejos de ser tal. Pues, siguiendo a Davidson, es posible interpretar el argumento de Wittgenstein acerca de la imposibilidad de un lenguaje privado sin validar un compromiso con el dualismo que contrapone lenguaje y habla en términos de una contraposición entre un esquema idealizado y su actualización. Esto exige entender que cuando Davidson niega que haya tal cosa como "el lenguaje", lo que está negando es que sea necesario reconocer la existencia de un esquema que se actualiza en cada instancia de habla.

Lo que vuelve exitosa una determinada interpretación de lo que alguien dice es la circunstancia de que hablante y oyente se entienden acerca de algo que se encuentra en el mundo, esto es, en el mundo que

${ }^{86}$ Davidson (2005), p. 107.

${ }^{87}$ Davidson (2001a), p. 276

${ }^{88}$ La amplia gama de interpretaciones existentes vuelve controversial la determinación del locus específico en que se encontraría desarrollado el argumento de Wittgenstein. La interpretación más ortodoxa favorece la comprensión del argumento como directamente referido al problema de las percepciones sensoriales, cuyo desarrollo se encontraría en los $\S \S 243$ y siguientes de las Investigaciones Filosóficas. Así por ejemplo Tugendhat (1979), pp. 91-113. Una interpretación diferente, sumamente influyente, según la cual el desarrollo del argumento como tal se encontraría antes, como refutación del escepticismo acerca de la objetividad de la pregunta por el seguimiento de una regla, se debe a Kripke (1982), pp. 55-113. 
habitan ambos. Por eso, todo entendimiento asume la forma de una triangulación, pues sólo así es posible entender que hablante e intérprete llegan aplicar consistentemente un mismo concepto ${ }^{89}$. La pregunta acerca de qué es aquello del mundo ante lo cual reacciona una criatura — esto es, la pregunta por la objetividad - no se deja plantear si no hay otra criatura que a su vez pueda reaccionar ante la reacción de la primera. Y si no hubiera respuesta a esa pregunta, entonces tampoco habría respuesta a la pregunta acerca de qué lenguaje habla esa criatura ${ }^{90}$.

El carácter esencialmente público del lenguaje permanece incólume si uno rechaza la significación supuestamente constitutiva de un set de reglas que fijan condiciones universalmente necesarias para la comunicación. Hablar un lenguaje consiste en cultivar con otros la disposición recíproca a una atribución de significado progresivamente coincidente. Si llegamos a entender las palabras de otro, entonces compartimos una forma de vida ${ }^{91}$. Como escribe Davidson:

Asumir la posición de un intérprete es asumir conscientemente el estatus en que ha de encontrarse cualquiera que tenga pensamientos y actitudes, dado que las actitudes de una persona sólo tienen contenido - son interpretables - si esa persona está en comunicación con otras; sólo los intérpretes pueden ser interpre$\operatorname{tados}^{92}$.

Si es cierto, como se lee en el Tractatus, que "los límites de mi lenguaje son los límites de mi mundo"93, entonces no hay un mundo que pudiera ser mi mundo que a la vez no sea nuestro mundo. La objetividad, y en esto coincidirían Habermas y Davidson, tiene su asiento en la intersubjetividad ${ }^{94}$.

\section{La normatividad del entendimiento}

Lo anterior hace pertinente una reflexión final acerca de lo que cabe entender como la normatividad que es inmanente al lenguaje, hallazgo que está en el núcleo del programa filosófico de Habermas.

\footnotetext{
${ }^{89}$ Davidson (2001b), pp. 109-112, 119-121, 128-130.

${ }^{90}$ Ibídem, pp. 119-120.

${ }^{91}$ Davidson (2004), p. 37. Cfr. Wittgenstein (1984b), § 241.

${ }^{92}$ Davidson (2004), pp. 48-49.

${ }^{93}$ Wittgenstein (1984a), § 5.6.

${ }^{94}$ Davidson (2001b), p. 121; Davidson (2004), p. 143.
} 
La lectura propuesta por Krämer, y que aquí ha sido seguida, muestra que la normatividad que se esconde en la racionalidad que subyace a la posibilidad de entendimiento lingüístico recibe una estructuración jurídica latente en el esbozo habermasiano de una pragmática universal ${ }^{95}$. Pues ser capaz de desempeño lingüístico equivale, según Habermas, a ser capaz de contraer obligaciones para la posterior coordinación de la acción relativa al desempeño de pretensiones de validez, en virtud de la satisfacción de condiciones universales fijadas en reglas pragmáticas. Por eso es tan sugerente que, indagando en el dictum habermasiano según el cual "entendemos un acto de habla cuando sabemos qué lo hace aceptable", Albrecht Wellmer sostenga que el desarrollo consistente de la concepción habermasiana de la acción orientada al entendimiento tendría que traducirse en una comprensión general de las fuerzas ilocucionarias a partir del paradigma de los actos de habla regulativos ${ }^{96}$, que son aquellos, según ya se indicara, en que la pretensión de validez abiertamente tematizada por el hablante es una pretensión de corrección o rectitud normativa.

Aquí es necesario detenerse en la noción de una obligación cuya base misma pudiese ser lingüística. Defendiéndose frente a algunas críticas levantadas por Michael Dummet, precisamente en el sentido de una acusación de no dar cuenta del aspecto social del lenguaje, Davidson observa que resulta absurdo pensar que uno pudiese estar obligado en el marco de un lenguaje ${ }^{97}$. En la medida en que la cuestión concierna la comunicación lingüística, "nuestra única obligación, suponiendo que ésta sea la palabra adecuada, es hablar de una manera tal de poder lograr nuestro propósito siendo entendidos como esperamos e intentamos serlo"98. Es decir: puesto que sólo podemos desempeñarnos como hablantes en la medida en que seamos capaces de desempeñarnos como intérpretes, debemos hacer posible recibir una interpretación caritativa de otro, en la medida en que queramos ser entendidos.

La adopción del principio de caridad, como estrategia de acomodación racional en la atribución de significado a las palabras (y acciones) de otros, entraña un compromiso (débilmente) normativo ${ }^{99}$. La suposición de coherencia y correspondencia en las emisiones del otro, que

\footnotetext{
${ }^{95}$ Krämer (2001), pp. 90-91.

${ }^{96}$ Wellmer (2007), pp. 50-60, nota 33.

${ }^{97}$ Davidson (2005), pp. 109-123.

${ }^{98}$ Ibídem, p. 118.

${ }^{99}$ Véase Davidson (2004), pp. 129-130.
} 
es como se materializa la adopción del principio de caridad, significa partir de la base de que el interlocutor es alguien suficientemente parecido a uno mismo. Esto quiere decir que en la interacción lingüística sí se despliega una cierta normatividad. Pero si Davidson tiene razón, no se trata de una normatividad contractual por la cual queden obligados sujetos que esgrimen pretensiones entre sí. Se trata, más bien, de aquella normatividad que es propia del reconocimiento de mí mismo en los demás.

\section{BiBLIOGRAFÍA}

Austin, J. L. (1962). How to Do Things with Words. $2^{\mathrm{a}}$ ed. Cambridge, Mass.: Harvard University Press.

Chruchland, Paul (1999). Materia y Conciencia. Barcelona: Gedisa.

Davidson, Donald (2001a). Inquiries into Truth and Interpretation. $2^{\mathrm{a}}$ ed. Oxford: Oxford University Press.

(2001b). Subjective, Intersubjective, Objective. Oxford: Oxford University Press.

- (2004). Problems of Rationality. Oxford: Oxford University Press. (2005). Truth, Language, and History. Oxford: Oxford University Press.

Habermas, Jürgen (1984). Vorstudien und Ergänzungen zur Theorie des kommunikativen Handelns. Frankfurt a.M.: Suhrkamp.

(1998). Conciencia Moral y Acción Comunicativa. $5^{\mathrm{a}}$ ed. Barcelona: Península.

(1999). Teoría de la Acción Comunicativa, I. Madrid: Taurus.

(2003). Acción Comunicativa y Razón sin Trascendencia. Buenos Aires: Paidós.

Krämer, Sybille (2001). Sprache, Sprechakt, Kommunikation. Frankfurt a.M.: Suhrkamp.

Kripke, Saul (1982). Wittgenstein on Rules and Private Language. Cambridge, Mass.: Harvard University Press.

Mañalich, Juan Pablo (2007). “La Pena como Retribución”, Estudios Públicos 108: 117205.

Quine, W. V. O. (1960). Word and Object. Cambridge, Mass.: MIT Press.

Rorty, Richard (1979). Philosophy and the Mirror of Nature. Princeton, N.J.: Princeton University Press.

Searle, John (1968). "Austin on Locutionary and Illocutionary Acts”. The Philosophical Review 77: 405-424.

(1969): Speech Acts. Cambridge: Cambridge University Press. - (1979): Expression and Meaning. Cambridge: Cambridge University Press. (1995): The Construction of Social Reality. Nueva York: The Free Press.

Tugendhat, Ernst (1976). Vorlesungen zur Einführung in die sprachanalytische Philosophie. Frankfurt a.M.: Suhrkamp. (1979). Selbstbewußtsein und Selbstbestimmung. Frankfurt a.M.: Suhrkamp.

Wellmer, Albrecht (2004). Sprachphilosophie. Eine Vorlesung. Frankfurt a.M.: Suhrkamp. 
(2007). Wie Worte Sinn machen. Frankfurt a.M.: Suhrkamp.

Wittgenstein, Ludwig (1960). The Blue and Brown Books. Nueva York: Harper Torchbooks.

(1984a). Tractatus Logico-philosophicus. Werksausgabe, Tomo 1. Frankfurt a.M.: Suhrkamp.

- (1984b). Philosophische Untersuchungen. Werksausgabe, Tomo 1. Frankfurt a.M.: Suhrkamp.

Recibido: marzo 2010. Aceptado: junio 2010. 